Dilemmas 2015 Papers from the 18th annual International Conference Dilemmas for Human Services: Organizing, Designing and Managing

\title{
Suggestions on communications systems for off- shore vessels
}

Yushan Pan

Norwegian University of Science and Technology and University of Oslo, Norway, yushan.pan@ntnu.no

\begin{abstract}
Communications systems for marine operations are designed based on the concept of interactions between an individual person and those systems, while the interactive relations between multiple people and the systems are overlooked. Although extensive research focuses on designing systems that support cooperative work, requirements specifications for systems design do not support electrical engineers fully in devising cooperative systems. This paper records a case that took place at sea that resulted in unsafe operations due to insufficient development of communications systems. By using actor-network theory (ANT) to analyze and organize interactive relations of communications, the paper suggests focusing on interactive relations to help electrical engineers understand how to implement cooperative systems to support safety operations.
\end{abstract}

Key words: ANT, communications, safety.

(C) 2015 Yushan Pan. This is an Open Access article distributed under the terms of the Creative Commons Attribution-NonCommercial 4.0 International License (http://creativecommons.org/licenses/by-nc/4.0/), permitting all non-commercial use, distribution, and reproduction in any medium, provided the original work is properly cited. http://dx.doi.org/10.15626/dirc.2015.17

ISBN: 978-91-87925-74-0 


\section{Background}

During my fieldwork on a supply vessel, the communications systems proved difficult to use. When a given vessel communicates with an oil platform, other vessels around the platform are not supposed to hear these messages. In reality, such communications are disordered, and all the vessels around a platform can hear and respond to such messages. Moreover, the onshore center can also interject themselves into these communications. On one occasion, these issues caused such a serious misunderstanding that two vessels almost collided. Telecoms engineers are mainly responsible for designing communications functions. They design communications systems by following the concept of open channel communications, which means that everyone can broadcast messages within a specific area at sea (International Telecommunication Union 2009). There is a lack of understanding about how a group of operators should participate in a more complicated communications network, such as two vessels and a platform working together simultaneously but not on the same task. There are two reasons for selecting this safety breach. First, communications misunderstandings occur due to poor design of communication systems, which causes dangers to both vessels and people. To increase safety in offshore operations, communications systems are typical supportive tools that must be analyzed. Second, design researchers in Computersupported Cooperative Work (CSCW) could provide requirement specifications (Crabtree, 2003) to suggest communications systems design to support group operations (Schmidt, 2000; Arminen, 2001). However, they lack sufficient knowledge (Baxter and Sommerville, 2011) to translate cooperative work of marine operators in marine operations explicitly to telecoms engineers so that the latter group can organize functionalities of communications systems from an engineering perspective. Hence, this paper aims to answer how design researchers can explicitly highlight interactive relations for engineers by analyzing a communication case. It proposes that by organizing interactive relations, functionalities of communications systems could be redesigned to support safe cooperative work.

\section{Related work}

Researchers have investigated the best approaches to design for collaboration; they have adopted different perspectives in their studies. For example, some have explored systems requirements (Sommerville, Lock and Storer, 2012) and conducted ethnographic studies on work practices in different contexts, such as health care (Bardram, 1998), the London Underground (Heath and Luff, 1991), and onshore crane operations (Haavik, 2014). These studies all investigate work practices in situ, but do not address how technologies can be implemented from an engineering perspective (Baxter and Sommerville, 2011). A few studies focus on cooperative work in the maritime domain; for example, one researcher has concluded that physical and information spaces are not designed well and should be im- 
proved to reflect a richer understanding of work routines onboard ships (Pan 2016).

In engineering design, the first issues for engineers is a system's functionalities (Giffin et al., 2009). Engineers concern themselves with realizing functionalities in systems but often dismiss work practices (Greenwood and Sommerville, 2013). Among several design methods, design researchers bring users directly into design processes to produce what is really needed (Bjögvinsson, Ehn and Hillgren, 2012). Design researchers point out that interaction relations are central (Bjørn and Boulus-Rødje, 2015), but there is very little scholarship that makes clear how to highlight their nuances for electrical engineers. Hence, there remains a problem (Anderson, 2000) that how design researchers' insights should be effectively and efficiently translated to support engineers' notions of how systems should be devised.

\section{Theory and method}

ANT gives voice to technological artefacts (Cordella and Shaikh, 2003), which expand our understanding of how an interactive relation is created if humans interact with both other humans and nonhuman actors of some kind (Law, 1992). This is important for highlighting interactive relations, since incompatible interests from actants may result in breakdowns during offshore operations, which makes the weaknesses of a network visible. The translation of interests may then be inscribed into a medium, whether it is a technology and work procedure. The actants may support the translation to perform an enrolment (Bannon, 1991). The interaction relations may then be defined as actants in a network that have the same interests and aim at the same goal. This would help to provide a detailed solution for engineers who design cooperative systems. The case in the present study involves cooperative work among operators and communications systems, in which their interaction relations are shaped and reshaped during marine operations. ANT (Latour, 1990) is a natural theoretical lens through which to view these relations. I engaged with marine operators on the vessel in question for about a week to conduct interviews and observations of in situ work practice in March, 2015. Operators were presented with the purpose of the study and gave informed consent, as is required by the Norwegian Data Protection Authority.

\section{The case}

At the very beginning, an offshore vessel has to wait at a significant distance from a platform. The platform gives orders to specific offshore vessels, while an onshore center also coordinates offshore vessels to serve specific platforms. Communications in offshore operations often occur in fragments of dialogue. The conversations are primarily in English, but at sea there are sometimes phrases in Norwegian and Danish. Where those languages were used, they are translated into English in this paper.

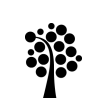

Papers from the 18th annual Dilemmas International Research Conference 
At the beginning, the communication was between an offshore vessel, Viking Princess (VP), and the oil platform:

Operator: Good day, this is Viking Princess (VP).

Platform: Good day, VP, this is Bergensfjord.

Operator: We are ready to work with you. Can we go now?

Platform: (No response).

Suddenly, the onshore center interjected itself into this communication:

Onshore: Good day, VP, please report your position.

Operator: Our position is 56 29'54.6"N 333'08.4"E.

Onshore: Ok. Go to Bergensfjord.

Operator: $O k$.

In this communication, the $V P$ operator did not confirm with the platform whether this response and direction came from the platform. The $V P$ operator sent an order to the engine room and the ship began to approach the platform. A few minutes later, the platform replied. However, this reply was to another vessel, Seabed Viking $(S V)$, rather than to $V P$. The operators on $V P$ could hear this communication.

Platform: We are not available right now. Please wait a moment [in Norwegian].

Operator (VP): Ok. Then we can standby, VP.

Platform: No, I mean not you [In Norwegian]!

Operator (VP): Ok. Then we are coming.

While this conversation was underway, pop songs could be heard. None of us knew where the music originated, but it was not from $V P$. No reply was received from $S V$, and we observed that $S V$ was also approaching the platform. Moreover, it was closer to the platform than $V P$. The platform did not call $S V$ immediately to stop it. Instead, the platform guided $V P$ to approach its crane \#3. However, the operator of crane \#3 on the platform did not notice that two vessels were approaching him at the same time from different directions. The operator on $V P$ did not report this issue, although he did observe it. Instead, the operator continued his own work. Suddenly, the onshore center called $V P$ :

Onshore: VP, VP, VP.

Operator (VP): Yes, VP.

Onshore: Please change your head a bit left. You can go to Moff platform when you finish this one.

Operator(VP): Ok. Thank you. 
The operator $(V P)$ did not realize that changing direction in this manner would later cause a problem. When the $V P$ operator found that $S V$ was positioning itself under the platform, he still did not report this to platform. The operator of crane \#3 did not recognize which ship was which. The operators on $V P$ barely managed to perform dynamic positioning operations to position $V P$ properly. There was still a little space between the two vessels at this time. Both vessels were under crane \#3, and they stopped at almost the same time, leading the crane operator to yell:

Platform: SV! I told you do not come too close [In Norwegian]. Operator (SV): Ah? I just heard you ask VP not to come [In Danish]. Platform: Oh, sorry! What did you say?

Operator (VP): Oh, so we stay away?

Operator (SV): Whom you are talking to? Me?

Platform: Sorry, I am not Norwegian; my Norwegian may confuse both of you just now. SV, could you move away? I cannot have you here right now.

Operator (SV): I cannot move. We are too close to VP.

Platform: VP, could you give a way to SV?

As the $V P$ operator was checked whether he could give way to $S V$, a voice came from the platform:

Platform: I am putting down cargo, please check.

Both vessels: What? No, wait! We are colliding!

Platform: Why? I confirmed with you just now. I saw you are alone there.

Both vessels: Who are you?

Platform: I am the operator for crane \#2.

The VP operator quickly looked around to determine whether there was another vessel nearby. He found another vessel under crane \#2 conducing offshore operations. At that moment, no one could recognize which order applied to whom, when, and for what reason; nor was it clear from whom the orders originated.

\section{Highlighting of interactive relations}

When examining these communications from an ANT point of view, each cooperative task, whether platform-vessel or onshore-vessel, can be seen as a network. Although VP operators were enrolled in several networks, these networks were different because they translated to different interests during operations. For example, the order from the onshore center caused confusion to the VP operator 
when the platform did not reply to the $V P$. When onshore requested $V P$ to change its direction slightly, that left $V P$ with almost no space to give way for $S V$.

Here, different networks became visible due to multiple breakdowns caused by different interests. When $V P$ called the platform, regardless of whether the platform replied, they were in the same interactive relation, because they had the same interest in this network: the safe positioning of $V P$ under the platform. Another interactive relation involves onshore and $V P$. This interactive relation is different than the former one, because this relation developed when the order was sent from onshore. Although the operator on VP was enrolled in both networks, the interests were different.

$S V$ ended up participating in the network because the communication systems were too open, causing an incorrect interactive relation during communications that could have been avoided if $V P$ was prohibited from accessing the network between $S V$ and the platform. There should have been a network that involved only the platform and $S V$.

After the shouting from the platform, $V P$ and $S V$ were in the same network, but the interactive relation between $V P$ and the platform and the interactive relation between $S V$ and the platform were different. When crane \#3 operator coordinated work with $V P$, the communication should have been blocked for $S V$. Meanwhile, crane \#2 operator should have made clear to whom he was speaking. The theoretical design insight from this episode is simple, but of vital importance for safety: when highlighting interactive relations, all actants in any specific network should be clearly identified. Otherwise, there could interactive relations which are not recognizable, because of conflicting interests. In this case, when a ship operator communicates with the platform, the actants should be made explicit, while the platform should also let the crane operator know which vessel is approaching.

The operators in this case tried to manage the communication chaos. However, some opportunities to solve problems were missed, such as confirming vessel names, reporting another vessel's activities in the same small area of the sea, and added barriers caused by the use of different languages.

When a network was created between the VP operator and the platform, the operator mistakenly thought that the onshore communication was actually a response from the platform, and thus did not know that his reply went to the onshore center. Although an order coming from the platform differs from one coming from onshore, the operator here simply followed those orders without any second thoughts. When the $V P$ operator was interviewed, he said:

I don't know why the requests were different. It seems they were not ready to give us a position. Maybe the guy who answered me didn't understand my reply? I just follow orders and do my best. 
However, when asked about the confusion regarding the orders, why he noticed that it was likely unsafe to change the vessel's direction, and whether he also knew that another vessel was approaching the same platform, the VP operator's answer raised the important issue of awareness:

I understood that if I changed the head direction of the vessel, that might have been unsafe but it seemed a very tiny thing that could be ignored. Everything will be recorded in the logbook, so I must follow orders. I also noticed that there was another vessel approaching the platform. I did not take any action because I thought that perhaps the platform knew it and that that vessel also knew what it was doing.

Here, the $V P$ operator was aware of what other people were doing, but only at a superficial level; everyone seemed to know what other people were doing. Design researchers might be able to interpret such a phenomenon while still being unable to offer a solution for it (Arminen, 2001). This challenge led to the operator's participating in multiple networks without knowing that his work might conflict with other operations on other vessels and the platform. The operator sometimes turned down the volume of the communications so he was not influenced by the chaos. Since he was unwittingly involved in different networks with different interests, no matter what action he took, there were potential safety issues surrounding his work. The barrier caused by different languages is another issue. The operator may not have caused this safety problem in the operations, but since he was part of a network, others' actions may have significantly affected him and caused unsafe operations. Therefore, a common language for communications combined with technically improved communications systems could support safety in cooperative work.

\section{Suggestions to design}

Interactive relations follow the interests of networks. Hence, the connections between different interactive relations also must be investigated in networks. The superficial awareness of the $V P$ operator can be used to clarify the relationship between interactive relations. Designing communications systems is thus about highlighting the connections between multiple interactive relations. This is crucial to providing safe operations from an engineering perspective, because it will help engineers have an idea of how to incorporate cooperative work and the connections between interactive relations into systems implementation. When considering cooperative work in systems development, the functions of systems also need to be organized according to the connections between interactive relations. In this case, engineers could combine such a system with other tools and systems that they already use regularly and integrate the additional system quickly without special help. Design researchers thus should deliver to engineers a means of how

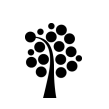

Papers from the 18th annual Dilemmas International Research Conference 
to construct cooperative systems, rather than simply interpreting what the system should look like.

In marine operations research, design researchers should not assume that simply specifying requirements will facilitate better systems implementation. Those specifications generally fail to capture the real-world performance of interactive relations among humans and nonhumans. From the ANT perspective, every time the operator works with communications systems to communicate with a relevant person or system, the network may change dynamically from the original interest to a new one. Furthermore, if there is a barrier involving different languages or a failure to confirm who is speaking, or both, the network becomes invalid, since interests may and almost certainly will conflict from time to time during operations. Humans may not know that they are going into an unsafe situation; instead, they continue to operate as directed because they may think that others are in the safety loop of an operation. Therefore, the operator did not know why he needed to stop the first time and change the ship's direction. The operator of crane \#3 was never aware that the operator of crane \#2 was also participating in the network and working with shipboard operators.

These kinds of problems are caused by current communications systems, which are developed with an emphasis on hardware. This approach means that each system alone can realize its basic communication functionality of allowing actants to interact with each other. However, this understanding completely overlooks the fact that communication is very diverse in real-world operations. When communication becomes network-based, a basic flow of control during communication is necessary. This requires a change in current communications systems to add a focus on the composition of connections among interactive relations. By highlighting these connections so as to recognize the importance of the outcomes of the interactions between operators and systems, the multiple networks involving operators, onshore, and platforms - networks that are discrete but overlapping - can become integral to the functionality of marine operations. By following work routes to assemble those units, it will be possible to re-organize the functionalities of cooperative systems for communications to support safe cooperative work.

\section{Conclusions}

After observing an unsafe marine operation caused by communication systems, I have suggested redesign work based on the analysis of interaction relations between marine operators and communications systems. Since an operation like an offshore oil platform includes multiple actants - the platform and its operators, the onshore center and its operators, and multiple vessels and their operators - safety could be significantly improved if communications were adequately controlled by ensuring that only actants in a given network could send or hear messages and that a common language was used. I contribute to scholarship by enabling design re- 
searchers to use interactive relations as a means to translate effective requirement specifications to engineers in designing cooperative systems. In this manner, the distance between design research and engineering design may be reduced.

References

Anderson, B., 2000. Where the rubber hits the road: notes on the development problem in workplace studies. In P. Luff, J. Hindmarsh, and C. Heath, ed. 2000. Workplace studies: recovering work practice and informing system design. Cambridge University Press, pp. 215-229.

Arminen, I., 2001. Workplace studies: the practical sociology of technology in action. ACTA SOCIOLOGICA, 44(2) pp. 183-189.

Bannon, L., 1991. From Human Factors to Human Actors - The Role of Psychology and Human-Computer Interaction Studies in Systems Design. Design at Work. Lawrence Erlbaum Associates, pp. 25-44.

Bardram, J., 1998. Designing for the dynamics of cooperative work activities. $A C M C S C W$. Seattle, USA.

Baxter, G. and Sommerville, I., 2011. Socio-technical systems: From design methods to systems engineering. Interacting with Computers, 23(1) pp. 4 17.

Bjögvinsson, E., Ehn, P. and Hillgren, P. A., 2012. Design things and design thinking: contemporary participatory design. Design issues, 28(3) pp. 101116.

Bjørn, P. and Boulus-Rødje, N., 2015. The Multiple Intersecting Sites of Design in CSCW Research. Computer Supported Cooperative Work, 24(4) pp. 319351.

Cordella, A. and Shaikh, M., 2003. Actor network theory and after: what's new for IS research? ECIS. Naples, Italy.

Crabtree, A., 2003. Designing Collaborative Systems - A Practical Guide to Ethnography. Springer.

Giffin, M., de Weck, O., Bounova, G., Eckert, C. and Clarkson, P. J., 2009. Change Propagation Analysis in Complex Technical Systems. J. Mech. Des, 131(8) pp. 1-14.

Greenwood, D. and Sommerville, I., 2013. Expectations and Reality: Why an Enterprise Software System Did Not Work as Planned. In R. Pooley, J. Coady, C. Schneider, H. Linger, C. Barry, and M. Lang, ed. Information Systems Development. Springer, pp. 51-62.

Haavik, T. K., 2014. Sensework. Computer-Supported Cooperative Work, 23(3) pp. 269-298.

Heath, C. and Luff, P., 1991. Collaborative activity and technological design: Task coordination in London Underground control rooms. ECSCW'91. Amsterdam, The Netherlands.

International telecommunication union. 2009. Manual for use by the maritime 
mobile and maritime mobile-satellite services. ITU-Radiocommunication.

Latour, B., 1990. On actor-network theory. A few clarifications plus more than a few complications. Philosophia, 25(3) pp. 47-64.

Law, J., 1992. Notes on the theory of the actor-network: Ordering, strategy, and heterogeneity. Systems practice, 5(4) pp. 379-393.

Pan, Y., 2016. Design of Digital Environments for Operations on Vessels. COOP'16, Trento, Italy, Springer.

Schmidt, K., 2000. The critical role of workplace studies in CSCW. In P. Luff, J. Hindmarsh, and C. Heath, ed. 2000. Workplace studies: recovering work practice and informing system design. Cambridge University Press, pp. 141-149.

Sommerville, I., Lock, R., and Storer, T., 2012. Information Requirements for Enterprise Systems. 17th Monterey Workshop, Oxford, UK. 